\title{
The importance of training
}

\author{
from Richard Pearson
}

\section{A recent study suggests ways in which the United Kingdom might improve industrial competitiveness by investing in training.}

THE United Kingdom's position in the world 'high-tech' league has become the focus for increasing concern over the past year. While the shortage of information technology skills has been the focus of much attention, and is a problem afflicting many other countries, a more disturbing manpower and skills problem for the United Kingdom has been highlighted in the latest audit of the country's performance, the report Competance and Competition (HMSO, 1984). This report seeks to contrast UK investment in training and human resources with that in West Germany, Japan, and the United States. Making international comparisons of educational qualifications and training investment can of course be notoriously difficult and lead to endless arguments, for example, over whether a Japanese engineering graduate is equivalent to one from West Germany or the United States. To get round this problem the report draws on a wide range of indicators to argue that the United Kingdom lags behind its major competitors in its investment in training and education, and it sets out an agenda for action to improve competitiveness and performance for the future.

While much of the recent national debate has highlighted the high tech skills, the report take as the foundation of a successful vocational educational and training (VET) system, the preparation of young people. The high participation rates of young people in education in the three countries is highlighted. In Japan 94, per cent of young people stay in education until the age of 18 , and 40 per cent go on to higher education or graduate school. In West Germany, nearly 70 per cent of school leavers go into VET and 20 per cent enter some form of tertiary education, while in the United States 73 per cent of those aged 16-24 are enrolled in school, college or university. By way of contrast, in the United Kingdom only just over half of the 16-18 age group participate in full-time education (Table 1). Emphasis on the 'three Rs'

Table 1 Participation in education by $16-18$ yr olds

\begin{tabular}{ll}
\hline Germany & $86 \%$ \\
Japan & $96 \%$ \\
UK & $60 \%$ \\
USA & $73 \%$ \\
\hline
\end{tabular}

*Age range 16-24 and competences such as team work, flexibility and 'learning to learn' rather than occupational knowledge and skills are seen to be important ingredients of successful VET systems. In terms of specific qualifications, 87 per cent of Japanese school leavers have a minimum qualification of upper secondary school diploma, 71 per cent of US school leavers have a highschool diploma and 90 per cent of West German school leavers have a school leaving certificate. But although 84 per cent of UK school leavers have three or more CSE graded passes, the report's authors believe that these qualifications are of a far less demanding nature.

At the other end of the scale the United States and Japan lead in the numbers of graduates, with West Germany and the United Kingdom on more equal footing

Table 2 New degrees per million of population

\begin{tabular}{lcc}
\hline & First degrees & Postgraduates \\
West Germany & 1,200 & 260 \\
Japan & 3,250 & 170 \\
UK & 2,000 & 380 \\
USA & 4,100 & 1,700 \\
\hline
\end{tabular}

(Table 2), although once again much depends on how comparable 'degree' qualifications are between countries. In terms of postgraduates, the United Kingdom moves into second place behind the United States, well ahead of both Japan and West Germany. An analysis on a subject basis shows the far heavier concentration of engineering graduates in both the US and Japan, but with Japan well behind the United Kingdom in terms of postgraduate scientists. What this brief synopsis suggests is that while the United Kingdom under-performs at lower educational levels, it scores far better at the much higher postgraduate levels. However, a recent report on British science, Foresight in Science - Picking the Winners, shows that despite this high output of scientists British science is not as successful as had been previously thought (Nature 312, 183; 1984).

Perhaps more revealing is the much higher priority that the three countries give to education and training, by the individual, employer and the state, and where the funding is regarded as necessary capital investment rather than as expenditure. Each however follows a different pattern. In both West Germany and Japan, employers takes a strong lead and make a high financial investment in education and training and in recent years have been increasing this investment despite the recession. A particular feature of the United States is the much high investment by the individual in training and retraining and the diversity of, and flexibility, in training provision. The prime motivation in the United States is seen to be competitive/economic from the point of view of the individual and the employer, although the role of government, at federal and state level, is seen as more volatile.

The report's aim is to provide a stimulus for debate about how to improve VET, and hence competitiveness, in the United Kingdom. It comments that VET provison has to be geared to suit the country's specific circumstances and that there is no one single model of success. And it recognizes that while a direct relationship between VET and economic success cannot be proved, every body of opinion in the three countries believes that economic success cannot be possible without a strongly sustained VET effort. A large number of recommendations of how to improve the United Kingdom's position are presented. They include education and training for young people to cope with the demands of working life, with a goal of 85 per cent of school- leavers achieving acceptable standards in a range of core subjects - an aim which is now government policy. The recent UK initiatives such as YTS and TVEI are seen to be moves in the right direction. For employers, there is a need to increase commitment to both on-the-job and off-the-job training as an investment in the future. They also need to take a lead in identifying training priorities and in increasing the status and rewards that acrue to jobs in the business sector. Flexibility in terms of easier access to training and retraining are also needed, while government investment in human resources has to be maintained. Finally, individuals need to be more aware that their own skills are relevant to their employment roles. Education and training is a collaborative affair and needs to be given a higher priority by all concerned if competencies and competitiveness are to be improved.

Richard Pearson is at the Institute of Manpower Studies, Mantell Buildings, University of Sussex, Brighton BN1 9RF, UK. 